\title{
DEVELOPMENT AND TESTING OF MULTI-LEVEL TEMPERATURE PROBE FOR UNDERWATER APPLICATION IN WETLAND SYSTEMS
}

\author{
I. J. Udom ${ }^{1,}{ }^{*}$, C. C. Mbajiorgu ${ }^{2}$ and L. Daniyan ${ }^{3}$

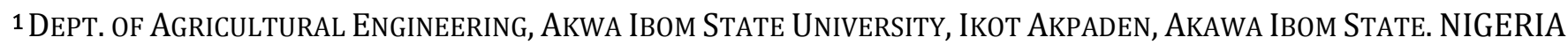 \\ 2DEPT. OF AGRICULTURAL AND BIORESOURCES ENGINEERING, UNIVERSITY OF NIGERIA, NSUKKA. ENUGU STATE, NIGERIA \\ 3 NASRDA CENTRE For BASIC SPACE SCIENCE, NSUKKa, ENUGU STATE. NIGERIA \\ E-mail addresses:1ikpeudom@aksu.edu.ng, ${ }^{2}$ const.mbajiorgu@unn.edu.ng,3danomartins@hotmail.com
}

\begin{abstract}
Temperature variation in wetland systems is of great importance. Temperature exerts a strong influence on chemical and biological processes leading to water quality treatment and is therefore important for wetland designers trying to both calculate accurate rates of treatment as well as optimize wetland systems for pollutant removal. Temperature fluctuations can result in thermal inversions. Temperature measurements are important for understanding hydrological and ecological processes in wetlands. Temperature measurements in underwater conditions is challenging in terms of cost and thorough insulation for optimal performance. This work presents the design and development of a waterresistant, adjustable multi-sensor temperature probe for underwater temperature measurement. It consists of three digital sensors DS18B20 interfaced with Atmega 328P microprocessor. The system is equipped with a $20 \times 4$ LCD display which displays up to three temperature profiles at varied depths. Validation of the instrument with the hand-held mercury-in-glass thermometer at different temperature regimes showed a $+1-0.5$ accuracy within a temperature range of $-10^{\circ} \mathrm{C}$ to $+85^{\circ} \mathrm{C}$.
\end{abstract}

Keywords: Constructed wetlands, temperature probe, sensors, water quality treatment, pollutant removal

\section{INTRODUCTION}

1.1 Wetlands Temperature Variations

Water temperatures in treatment wetlands are driven by energy gains and losses which are cyclical and act on both daily (diurnal) and seasonal time scales. As water flows through a wetland system the energy gain and losses drive the water temperature towards a balance point temperature at which energy gains equals energy losses. This results in a longitudinal change in water temperature as the system tends towards the balance point. The balance point temperature may be warmer or cooler than the influent water temperature depending on the relative magnitude of the energy flows [1].

The temperature of incoming and outgoing effluent is important because of its strong influence on the rate of microbial process leading to water quality treatment such as ammonia nitrogen processing [2-4]. Because temperature exerts a strong influence on some chemical and biological processes, it is important to wetland design in calculation of accurate rates of treatment as well as optimization of systems for pollutant removal. Temperature in tropical wetland systems is of concern in driving evaporative losses and may be an important water quality parameter in some situations.

\subsection{Wetland Temperature Variation Processes}

Major processes governing water temperatures in wetlands includes energy input such as solar radiation, convective heat transfer from the air vertical and lateral ground heat transfer and thermal energy from wetland inflows. Energy output from the wetland include solar back radiation, evapotranspiration, convective heat transfer from the air, vertical and lateral ground heat transfer, and energy exiting in wetland outflows.

Additionally, the change in energy storage, which is particular to the types of treatment wetland, its porous media, and vegetation, is needed to obtain a closed energy budget which can be written as [1].

Energy inputs - Energy outputs = Change in Energy storage

$\left(\mathrm{R}_{\mathrm{N}}+\mathrm{H}_{\mathrm{a}}+\mathrm{U}_{\mathrm{wi}}\right)-\left(\lambda_{\mathrm{m}} \mathrm{PET}+\mathrm{U}_{\mathrm{wo}}+\mathrm{G}+\mathrm{C}_{\mathrm{L}}\right)=\Delta_{\mathrm{S}}$

In (1), $C_{\mathrm{L}}$ is the lateral heat loss to ground, $M J / \mathrm{m}^{2} . \mathrm{d}, \mathrm{G}$ is the vertical conductive loss to ground, $\mathrm{MJ} / \mathrm{m}^{2} . \mathrm{d}$, ET is the water loss to evapotranspiration, $m / d, H_{a}$ is the convective transfer from air, $M J / m^{2} . d, R_{N}$ is the net 
radiation absorbed by wetland, $\mathrm{MJ} / \mathrm{m}^{2} . \mathrm{d}, \Delta_{\mathrm{s}}$ is the energy storage change in the wetland, $\mathrm{MJ} / \mathrm{m}^{2} . \mathrm{d}, \mathrm{U}_{\mathrm{wi}}$ is the energy entering with water, $\mathrm{MJ} / \mathrm{m}^{2} . \mathrm{d}, \mathrm{U}_{\mathrm{wo}}$ is the energy leaving with water, $\mathrm{MJ} / \mathrm{m}^{2} . \mathrm{d}, \lambda_{\mathrm{m}}$ is the Latent heat of vaporization of water, $\mathrm{MJ} / \mathrm{kg}\left(2.453 \mathrm{MJ} / \mathrm{kg}\right.$ at $\left.20^{\circ} \mathrm{c}\right)$ and $\rho$ is the density of water, $\mathrm{Kg} / \mathrm{m}^{3}$. In tropical wetlands, solar radiation is the primary energy input. Solar radiation varies diurnally and annually with the albedo (fraction reflected from the wetland surface) varying with vegetation and amount of open water areas.

Conductive losses and gains are typically small enough to be considered negligible except during very cold seasons of the year. Convection can either add or take away energy from the wetland while ET only removes energy from the system. Evaporation dissipates energy from the wetland water surface, thereby reducing wetland water temperature, while transpiration dissipates energy from the vegetation and cools plants surfaces rather than water temperature.

The energy flows that determine water temperature and the associated evaporative losses are shown in Figure 1. A treatment wetland may contain one or two thermal regions, depending on water loading (detention time). For long detention times, there is an inlet region in which water temperatures adjust to the prevailing meteorological conditions, and an outlet region in which that adjustment is complete.

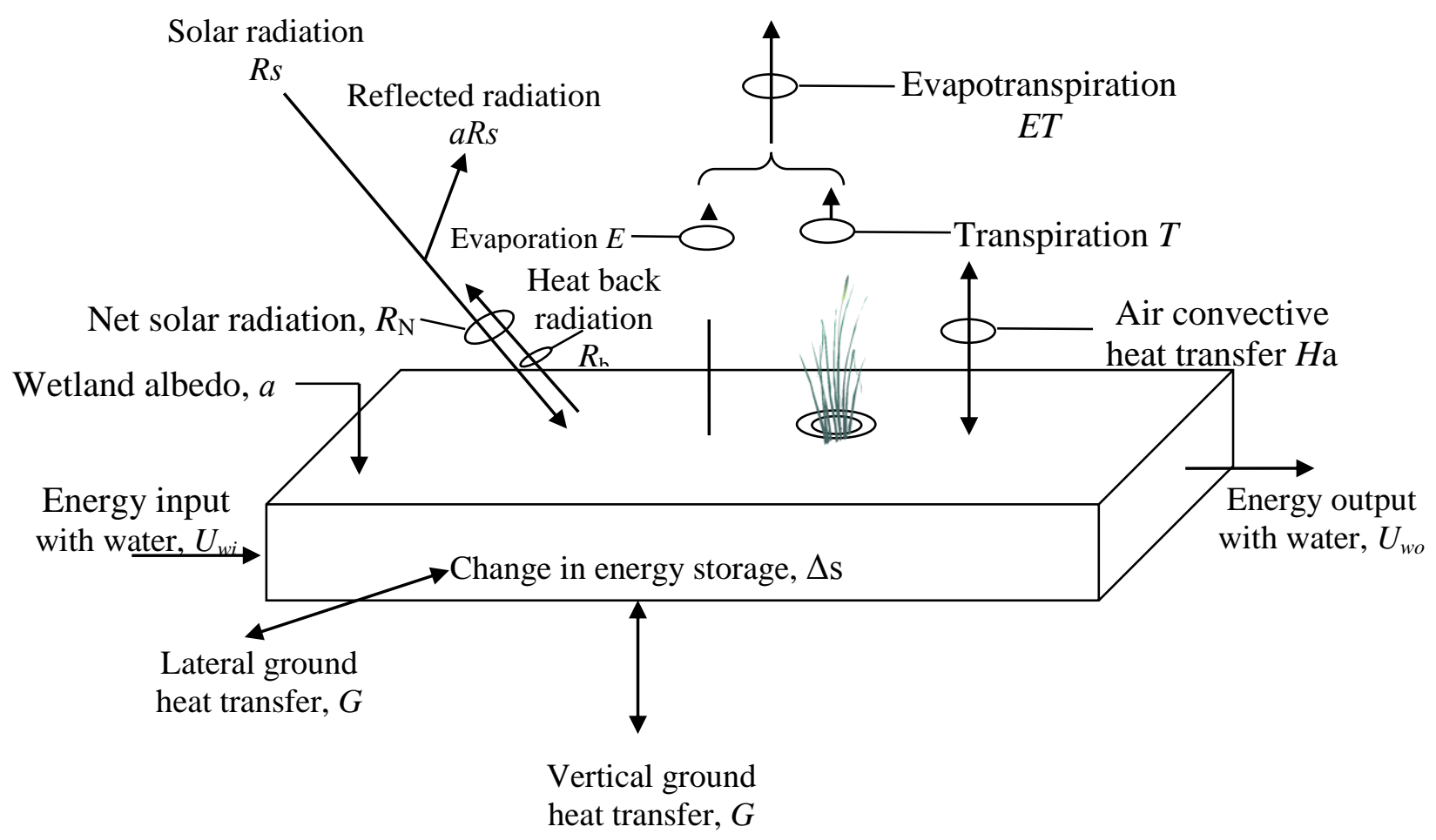

Figure 1: Components of wetland energy balance (Adapted from Kadlec and Wallace [5])

Table 1: Characteristics of different types of sensors

\begin{tabular}{llll}
\hline & \multicolumn{1}{c}{ Thermocouple } & \multicolumn{1}{c}{ RTD } & \multicolumn{1}{c}{ Thermistor } \\
\hline Cost & Low & High & Low \\
Temperature Range & Very wide: $-350^{\circ} \mathrm{F}+3200^{\circ} \mathrm{F}$ & Wide: $-400^{\circ} \mathrm{F}+1200^{\circ} \mathrm{F}$ & Short to medium: $-100^{\circ} \mathrm{F}+500^{\circ} \mathrm{F}$ \\
Interchangeability & Good & Excellent & Poor to fair \\
Long-term Stability & Poor to fair & Good & Poor \\
Accuracy & Medium & High & Medium \\
Repeatability & Poor to fair & Excellent & Fair to good \\
Sensitivity (output) & Low & Medium & Very high \\
Response & Medium to fast & Medium & Medium to fast \\
Linearity & Fair & Good & Poor \\
Self-heating & No & Very low to low & High \\
Point (end) Sensitive & Excellent & Fair & Good \\
Lead Effect & High & Medium & Low \\
Size / Packaging & Small to large & Medium to small & Small to medium \\
\hline \multicolumn{2}{c}{ Source: The Engineering Toolbox (http://engineeringtoolbox.com/temperature-sensors-d $448 . h t m l$}
\end{tabular}


After adjustment, temperature does not change further with distance, or detention time. The value reached is determined by the balance of energy flow and is termed the balance temperature [5]. In surface flow treatment wetlands, water temperature is most strongly related to air temperature.

Daily meteorological variations in air temperature cloudiness, windiness and relative humidity cause responses in water temperature, as do changes in incoming water temperatures.

\subsection{Vertical Temperature Stratification in Wetlands}

Changes in water temperatures may result in layers of water with different densities, and partition the water column into discrete density/temperature layers [6]. In hot seasons, solar radiation raises the temperature of the surface water, reducing its density. The less dense surface water is buoyant relative to the cooler (and denser) water layer underneath.

While thermally - induced vertical stratification in lakes is typically thought of in terms of long-term seasonal effects, daily stratification can also occur due to the diurnal fluctuation in solar radiation [1]. Wind speed is the primary determinant for stratification of shallow ponds [7] and the presence of vegetation promotes turbulence induced by water flow, but suppresses mixing caused by wind shear. Emergent vegetation canopies intercept a significant fraction of incident radiation, and thus prevent heating of the top layer of water. Therefore, the most extreme case would be expected for submerged aquatic vegetation, which can efficiently intercept radiation within the top layer of the water column, due to submerged leaves, yet inhibit wind and flow induced mixing [8]. In horizontal sub-surface flow (HSSF) wetlands, vertical stratification is inhibited by the thermal inertia of the wetland bed media. Further, solar radiation does not impinge directly on the water body, but is intercepted by the canopy and top layer of the gravel. As a consequence, stratification is minimal.

Vertical profile measurements of temperature in a subtropical constructed wetland in South Florida [8] in open water areas and sites dominated by emergent, floating or submersed vegetation over an annual cycle showed that open water sites were nearly isothermal and had minimal thermal stratification, while vegetated sites were all thermally stratified to some degree. The highest surface water temperatures $\left(>35^{\circ} \mathrm{c}\right)$ occurred in submersed vegetation where much light absorbed by the leaves and stems was reflected as heat. Long term monitoring at a vegetated site revealed periods of inverse thermal stratification in temperatures at the bottom compared to open water.
Investigations conducted on a set of four pilot scale subsurface flow (SSF) constructed wetlands to characterize heat transfer, mass dispersion and biological performance mechanisms from post construction through unplanted hydraulic base line studies to the states of mature stands of phragmites austral is indicate that in unplanted beds, daily thermal (temperature) fluctuations are depth dependent and range from $1-9^{\circ} \mathrm{C}$ [9]. These fluctuations result in daily thermal inversions and enhanced mixing and oxygen transport. For planted beds, thermal fluctuations are depth independent, have constant amplitude of $2^{\circ} \mathrm{C}$ and may be thermally stratified.

\subsection{Vertical Temperature Measurement.}

Vertical temperature measurement is important for understanding hydrological and ecological processes in wetlands. . Measuring vertical temperature profiles is costly and difficult [10]. It involves measurement of temperature values along the vertical profile (depth) of a wetland. Mercury in-glass thermometers are commonly used for repeated measurements along the given water depth. Temperature probes designed for multi-depth (level) application improves the accuracy of wetland water temperature sampling, over mercury-in-glass thermometers, by providing a one-time sampling of multiple depths thereby obviating time-gap errors in reporting temperatures taken repeatedly and alternately with mercury in-glass thermometers.

Temperature probes are devices used to measure temperature using contact-style sensing methods. These methods infer temperature by using probes to measure changes in a temperature-sensitive characteristic (such as voltage difference or resistance). Temperature probes consist of sensor junctions in direct contact with a metal or plastic casing. The casing of the probe makes contact with the system/media being measured and the sensors within the casing typically measure a voltage difference or resistance. Depending on the configuration, one sensor may be in contact with a reference system of known temperature for calibration. Table 1 compares the properties of the different types of sensors.

\subsection{Temperature Probe Application Examples}

Selkar, et al [11] successfully adapted a Distributed Temperature Sensor (DTS) system commonly used in civil infrastructure applications for multipoint temperature monitoring of a pilot wetland intended to lower temperature and ammonia during annual operational periods in the floodplain of the Pudding 
River near the City of Woodburn, Oregon, USA. The DTS system used optical fibres, commonly utilized in telecommunication cables, as distributed sensors. Details of DTS functioning can be found in [12].

Previous designs of multipoint temperature meters were built using LM35 or LM36 sensors. An example is the work reported in Nigeria by [13] using LM 35 as the sensor. These series of analog sensors are used for surface temperature measurement and thorough insulation is critically needed before they could be adopted for underground or underwater experiments. Besides being analog, their signal output depreciates with increasing distance between the analog sensors and the microcontroller, hence the integrity of their data outputs are often affected. This is a major reason why such sensors are subjected to critical calibration. Most of such systems depend on external power sources which makes such project not portable.

Also, there is need to overcome the setbacks of these previous sensors such as saving microcontroller resources and time required for program execution by reading all attached sensors on a simple microcontroller digital pin or bus line using the serial on the ROM embedded in each of the digital sensor.

The objective of this work is to develop a multilevel temperature probe for underwater applications in constructed wetlands using DS18B20 sensors.

\section{MATERIALS AND METHODS}

Three DS18B20 digital sensors were interfaced to Atmega 328p equipped with 20x4 LCD for data display. An indigenous base board was designed for the Atmega processor to enable us decide and define the capabilities, resources and level of miniaturization of the base board. The sensor lines are arranged on a calibrated dip - stick scale for sensor depth variation. Outputs from these sensors are digital and hence do not depreciate with distance from the microcontroller. The sensor is water proofed and encapsulated in aluminum foil for rugged task such as under- water and underground environments. Two rechargeable lithium cell of 2,620mAh capacity each are combined to realize $5,240 \mathrm{mAh}$ capacity of rechargeable and robust internal power supply to enhance the portability of the instrument.

The design was first simulated on Proteus Software environment and then implemented. The sensor features include,

-Serial embedded EEPROM

$-55^{\circ} \mathrm{C}$ to $+125^{\circ} \mathrm{C}$ operation range.

-Parasitic power mode operation and,

-Multi drop capacity.

The architecture of the design as done on Proteus and exported is shown in Figure 2. The implementation was done using the materials shown in Bill of engineering measurement and evaluation of Table 2 .

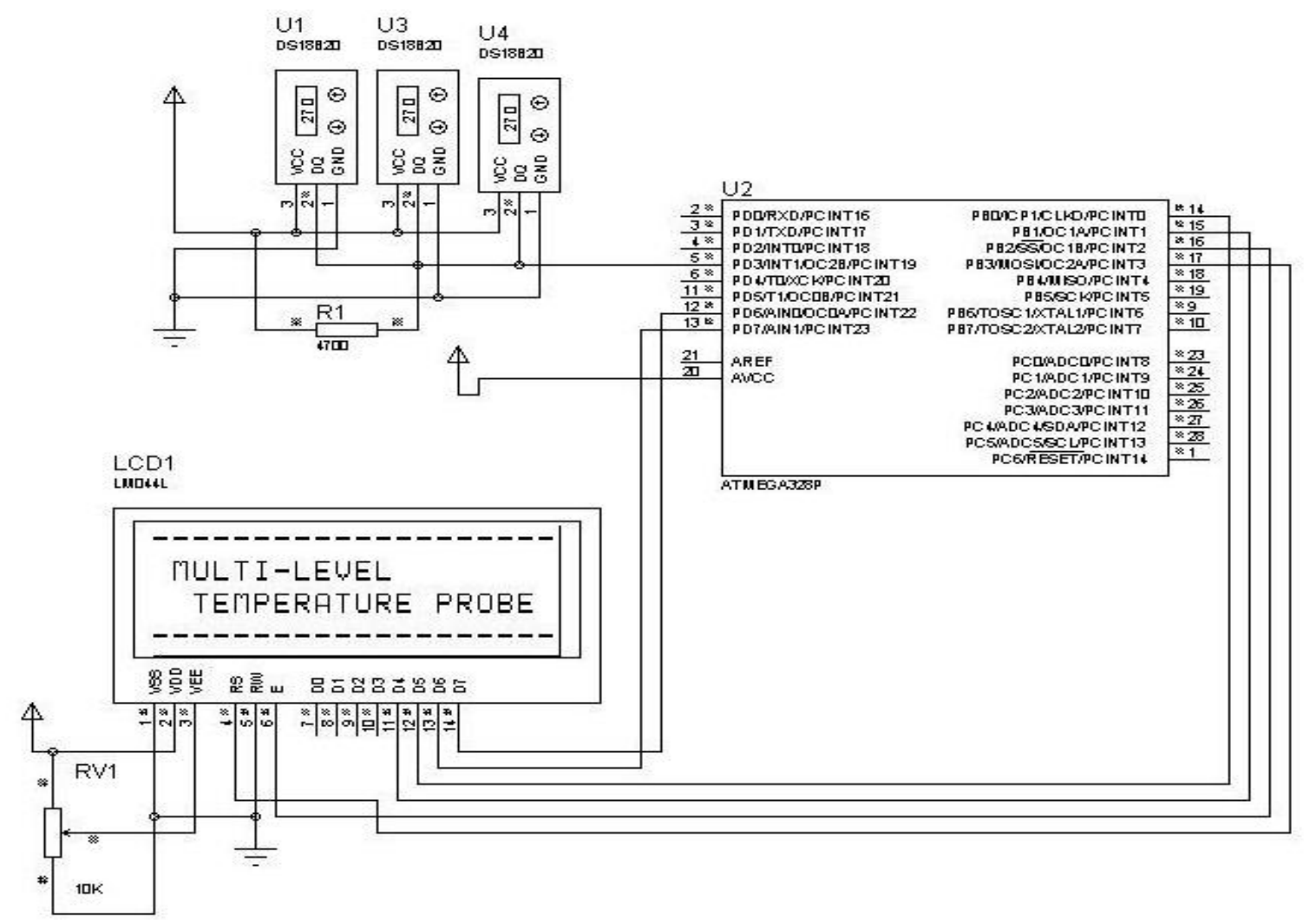

Figure1: The architecture of the probe design 


\subsection{Operation of the temperature probe}

The probe was applied at Nkek Idim wetland located along Abak - Ukanafun highway in Ukanafun Local Government Area of Akwa Ibom State (Figure 3). Upon power up, the system initializes in 13 seconds. The system thereafter performs data collation by taking five sample readings from each of the three sensors; a sample in 3 seconds. It then performs averaging on the set of collated values from each sensor and outputs the average values from each sensor on the LCD in 15 seconds. These data are held on the screen for about 12 seconds before the next round of data collation and averaging. The photo view of the constructed multilevel temperature probe and its onsite applicationis shown in Figure 3.

\section{RESULTS}

The multilevel temperature probe data sets were validated using mercury-in-glass hand-held thermometer at different temperature regimes.

Table 2: Bill of Engineering Measurement and Evaluation for the Equipment

\begin{tabular}{|c|c|c|c|c|c|c|}
\hline $\mathrm{S} / \mathrm{N}$ & ITEM & DESCRIPTION & QUANTITY & UNIT & RATE $(\mathrm{N})$ & AMOUNT(N) \\
\hline 1 & DS18B20 & $\begin{array}{l}\text { Waterproof } \\
\text { Temperature Sensor }\end{array}$ & 3 & Nos & 2,000 & 6,000 \\
\hline 2 & Atmega 328P & Microprocessor & 1 & No & 1,500 & 1,500 \\
\hline 3 & LCD & 20x4 LCD Display & 1 & No & 4,000 & 4,000 \\
\hline 4 & Lithium Cells & $\begin{array}{l}\text { 2,620mAH Lithium } \\
\text { Cells }\end{array}$ & 2 & Nos & 3,000 & 6,000 \\
\hline 5 & $\begin{array}{l}\text { Charging } \\
\text { Module }\end{array}$ & $\begin{array}{l}1 \text { Ampere } \\
\text { Micro Charger }\end{array}$ & 1 & No & 1,000 & 1,000 \\
\hline 6 & Circuit Board & Circuit Design Board & 1 & No & 400 & 400 \\
\hline 7 & Switch & $\begin{array}{l}\text { Power / LCD light } \\
\text { Switches }\end{array}$ & 2 & Nos & 30 & 60 \\
\hline 8 & Flex Cables & Connecting wires & 1 & Yard & 300 & 300 \\
\hline 9 & $\begin{array}{l}\text { Automobile } \\
\text { Paints }\end{array}$ & $\begin{array}{l}\text { White, Black and } \\
\text { Clear Auto Paints }\end{array}$ & 3 & Cans & 400 & 1,200 \\
\hline 10 & 1.5m Dip Stick & $\begin{array}{l}\text { Calibrated, Water } \\
\text { resistant Stick }\end{array}$ & 1 & No & 1,500 & 1,500 \\
\hline 11 & $\begin{array}{l}\text { Weather } \\
\text { Resistant } \\
\text { Casing }\end{array}$ & Packaging Box & 1 & No & 500 & 500 \\
\hline
\end{tabular}
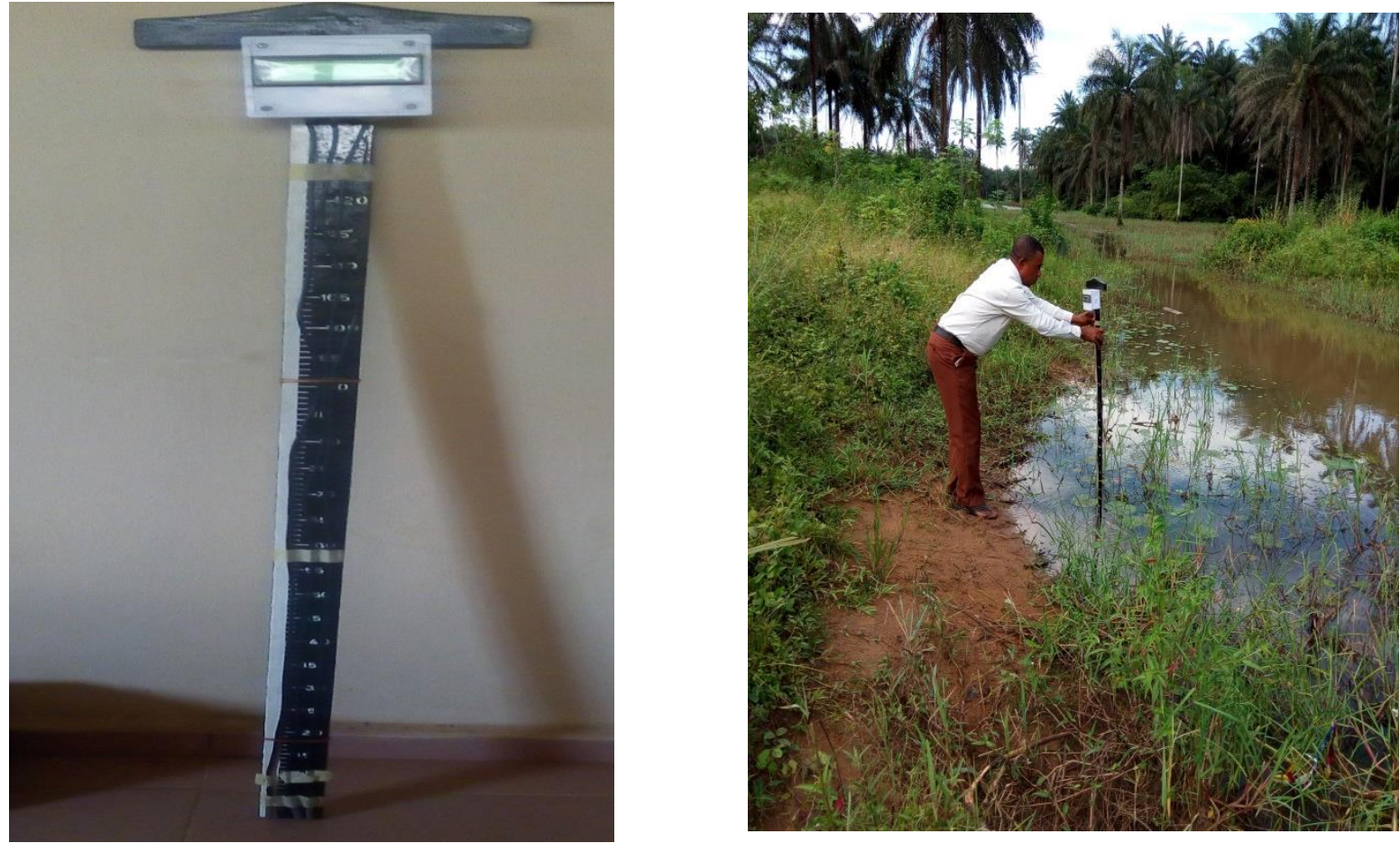

Figure 3: Photo view of constructed temperature probe and its application 
This was done by immersing the instrument together with the hand-held thermometer in the wetland to sense different degrees of hotness or coldness at four hourly intervals between 6 am - 6 pm during the days of the 10 $-14^{\text {th }}$ October, 2016 .The operational range of the employed mercury-in-glass thermometer was from $35^{\circ} \mathrm{C}$ to $44^{\circ} \mathrm{C}$, thus the data validation was carried out within this temperature boundary. The result is presented in Table 3.

Table 3: Validation data for temperature probe.

\begin{tabular}{ccc}
\hline $\begin{array}{c}\text { Validation } \\
\text { Sequence }\end{array}$ & $\begin{array}{c}\text { Mercury-in Glass } \\
\text { Thermometer }\end{array}$ & $\begin{array}{c}\text { Multilevel } \\
\text { Temperature } \\
\text { Probe }\end{array}$ \\
\hline $6 \mathrm{am}$ & 28.9 & 28.8 \\
$9 \mathrm{am}$ & 29.3 & 29.0 \\
$12 \mathrm{pm}$ & 31.7 & 31.5 \\
$3 \mathrm{pm}$ & 32.3 & 32.1 \\
$6 \mathrm{pm}$ & 30.0 & 29.8 \\
\hline
\end{tabular}

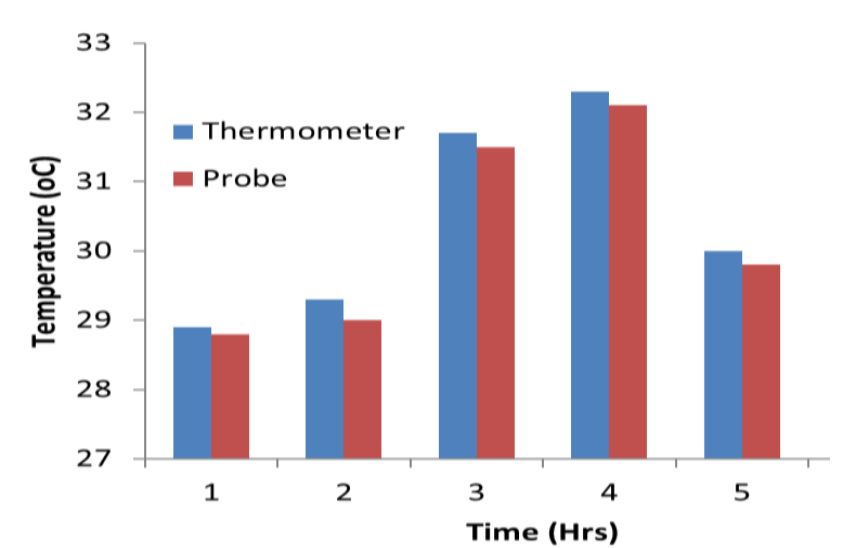

Figure 4: Comparison of temperature measurements using mercury-in-glass thermometer and temperature probe.

\section{ANALYSIS AND DISCUSSION OF RESULTS VALIDATION SEQUENCE}

The measurements performed with the multi-level temperature probe compared well with the measurements performed with the mercury-in glass thermometer as shown in Figure 4.

On the average, the measurements performed using multilevel temperature probe is lower than that of the mercury-in glass thermometer within the operational temperature range. This may be caused by the differences in the sensitivities (response time) of the two instruments. However, analysis of the data sets at $5 \%$ confidence level showed that there is no significant difference between the two temperatures.

\section{CONCLUSION}

Below-surface temperatures in constructed wetlands are of interest for several reasons including estimation of the water balance temperature and the modulation of microbial processes by root zone temperature. Multiple depth temperature sampling improves the accuracy of wetland water temperature sampling, over mercury-inglass thermometers, by providing a one-time sampling of multiple depths thereby obviating time-gap errors in reporting temperatures taken repeatedly and alternately with mercury in-glass thermometers. Among the available multi-depth temperature probes, none have used DS18B20 digital sensors. Their use in the design of this instrument was chosen principally because their signal output does not depreciate with increasing distance between the analog sensors and the microcontroller, hence the integrity of their data outputs are not affected. Additionally, the system does not depend on external power source which makes the instrument very portable. Regular maintenance is not required beyond replacement of the battery when it runs down and, the instrument can be integrated to a datalogger when the need arises.

\section{REFERENCES.}

[1] Kadlec, R. H. Wastewater treatment at the Houghton Lake wetland: Temperatures and the energy balance, Ecol. Eng. Vol. 35 (9), pp. 13491356. 2009.

[2] Kadlec, R. H., and S. D. Wallace. Treatment Wetlands, second ed. CRC Press, Boca Raton, FL. 2008.

[3] Picard C. R., Fraser, L. H., and D. Steer. The interacting effects of temperature and plant community type on utrient removal in wetland microcosms, Biores. Technol. Vol. 96, pp. 10391047. 2005.

[4] Faulwetter J. L., Gagnon, V., Sundberg, C., Chazarenc, F., Burr, M. D., Brisson, J., Camper, A.K., and O.R. Stein Microbial processes influencing performance of treatment wetlands: a review, Ecol. Eng. Vol. 35, pp. 987-1004 2009.

[5] Kadlec, R. H., Water temperature and evapotranspiration in surface flow wetlands in hot arid climate. Ecological Engineering 26:328 - 340. 2006.

[6] Wetzel, R. G. Limnology. Lake and River Ecosystems. Third edition. Academic Press: San Diego, California. 2001.

[7] Breen P.F and Lawrance, I. Design guidelines: Storm water Pollution Control Ponds and Wetland. The Cooperative Research Centre for Freshwater Ecology: Canberra, Australia http://ewater.org.au/archive/crcfe/freshwater/pu blications.nsf/). 1998. 
[8] Chimney M. J., Wenkert, L. and Pietro, R. C. Patterns of vertical stratification in a Sub-tropical constructed wetland in South Florida (USA). Ecological Engineering, 27(4):322 - 330

[9] Mc Nevin D; M. Harrison, A.king, K. David, C. Mitchell Towards and integrated performance model for subsurface flow constructed wetlands. Journal of Environmental Science and Health part A 35 (8): 2006.

[10] Naranjo, R. A multi-depth temperature probe for investigating subsurface heat transport. United States Hydrological Service Newsletter. Issue 18. March, 2015.

[11] Selker, J. S., The venaz, L., Huwald, H., Mallet, A., Luxemburg, W., Van de Giesen, N., Stejskal, M.,
Zeman, J., Westhoff, M., and M.B. Parlange Distributed fiber-optic temperature sensing for hydrologic systems. Water Resour. Res., Vol. 42: W12202. 2006a.

[12] Dakin, J. P., D. J. Pratt, G. W. Bibby, and J. Ross Distributed optical fiber Raman temperature sensor using a semiconductor light-source and detector, Electron. Lett., Vol. 21(13), pp. 569-570, oi:10.1049/el:19850402. 1985.

[13] Ojike, O., C. C Mbajiorgu, E .Anoliefo, W. I., Okonkwo Design and analysis of a multipoint temperature data logger. Nigerian Journal of Technology, Vol. 35, No. 2, April 2016, pp. 458 - 464, 2016. 